\title{
NASIB PEREMPUAN DI TANGAN LAKI-LAKI: ANALISIS LINGUAKULTURA PERIBAHASA RUSIA
}

\author{
Trisna Gumilar \\ Program Studi Sastra Rusia FIB Unpad \\ trisna.gumilar@unpad.ac.id \\ Hilman Fauzia Khoeruman \\ Program Studi Sastra Rusia FIB Unpad \\ hilman.fauzia@unpad.ac.id
}

\begin{abstract}
Abstrak
Peribahasa dalam konteks Rusia tidak hanya terbatas pada struktur dan makna, lebih dari itu melibatkan budaya. Memahami pola pikir, cara pandang, dan nalar masyarakat Rusia dapat ditempuh melalui peribahasa. Dalam hal ini peribahasa menjadi salah satu objek kajian dari lingkup linguakulturologi. Bidang tersebut menyajikan bagaimana bahasa berperan dalam penyampaian maupun penyebarluasan budaya dalam arti sosio-humaniora. Dalam artikel ini dibahas bagaimana Eksistensi perempuan direpresentasikan oleh peribahasa Rusia. Metode kualitatif dianggap cukup memadai untuk membongkar masalah sosio-humaniora, termasuk untuk menganalisis peribahasa. Pemaparan analisis data disampaikan secara deskriptif. Konsep linguakulturologi dari Gasanoca (2016), Fedorov (2014), dan Farkhutdinova (2000) dijadikan sebagai landasan teori penulisan artikel ilmiah ini, sedangkan konsep peribahasa Dahl (2003) menjadi lingkup data artikel. Simpulan artikel berupa gambaran eksistensi perempuan dalam peribahasa Rusia yang dipersepsikan secara semantis sebagai pihak yang dikuasai baik itu secara sosial, stereotifikasi, dan patriarki.
\end{abstract}

Kata kunci: peribahasa, perempuan, linguakulturologi

\begin{abstract}
Proverbs in the Russian context are not only limited by structure and meaning, but also involved the culture. Insight of the mindset, worldview and reasoning of Russian society can be reached through proverbs. In that case proverbs appear as object of study in the linguaculture scope. It presents how language plays a role in the delivery and dissemination of culture in the term of socio-humanities. In this article discusses how the existence of women represented by Russian proverb, which is related to the linguacultureology study. Qualitative methods are considered sufficient to uncover socio-humanities problems, including to analyze proverbs. Data analysis is presented descriptively. Linguakulturology concept of Gasanova (2016), Fedorov (2014), and Farkhutdinova (2000) was used as the theoretical basis in this writing, while the concept of proverb Dahl (2003) was used as scope of the data. The conclusion of the article is the existence of women in russian proverbs are perceived semantically as being socially controlled, stereotified, and patriarchaly.
\end{abstract}

Keyword: proverbs, women, linguaculturology

\section{PENDAHULUAN}

Sebagai bagian dari folklor lisan yang diproduksi secara orisinal di dalam sebuah budaya, peribahasa merupakan manifestasi pemikiran, nalar dan cara pandang masyarakat penuturnya. Hal ini menuntun para peneliti untuk meletakan 
peribahasa sebagai sumber studi bahasa dalam kaitannya dengan budaya (linguakultura). Oleh karena Peribahasa memiliki bentuk yang membeku (terbakukan) (Kridalaksana, 2008) dan tidak banyak berubah, memiliki pola yang hampir merata (Permyakov, 1988; Dahl, 2003; Mieder, 1993), maka peribahasa bukan saja menjadi fenomena linguistik yang orisinal tetapi juga menjadi cerminan bangsa (Dundee, 1980; Ivanov, 2006; Mieder, 1993).

Tidak mengherankan apabila peribahasa menjadi sumber informasi penting dalam mempelajari karakter dan identitas bangsa. Mempelajari peribahasa Rusia baik dalam konteks folklor, sejarah. maupun perkembangannya, secara teoretis dan praktis memiliki peran untuk mengetahui standar moral secara umum, kebiasaan, larangan dan kebiasaan bangsa Rusia dalam praktik sehari-hari ; peribahasa adalah kekayaan etnografis, kata mutiara, menghiasi pembicaraan, dan memberikan gambaran identitas; memahami dasar-dasar filsafat rakyat; peribahasa sangat penting dalam mempelajari bahasa asli; mengenalkan kearifan lokal; memahami pola komunikasi Bangsa Rusia. Hal tersebut, sejalan dengan definisi peribahasa sebagaimana ditulis dalam Kamus Besar Bahasa Rusia (Ozegov, ) ujaran rakyat yang singkat dan populer dengan konten didaktis.

Bagi Dahl (2003) pola peribahasa memiliki dua struktur yaitu penilaian, larangan atau petunjuk pada satu lapis, dan pernyataan yang lugu pada lapis lainnya. Artinya, meskipun seringkali dibungkus dalam bahasa figuratif, peribahasa tetap menyajikan penilaian yang gamblang terhadap sebuah objek dan karenanya relatif berterima pada masyarakat tanpa ada konfilk terhadapnya. Sebagai contoh, dapat dilihat pada peribahasa berikut:

(1) Собака умней бабы: на хозяина не лает

"Sobakaumneibaby: nakhozyananelaet"

'Anjing lebih baik dari istri: ia tak menggonggong majikannya'

Makna peribahasa (1) adalah ungkapan ketidak puasan, sebuah pernyataan yang sesungguhnya tidak berhubungan baik dengan anjing ataupun perempuan (istri). Meskipun demikian, penggunaan nomina баб $a^{\prime} \mathrm{baba}^{\prime \prime}$ perempuan" (kelas bawah yang telah menikah) sebagai figuratif dan disandingkan dengan Собака'sobaka'"anjing", jika dibaca secara harafiah dapat bermakna pejorative. Sejauh ini tidak ada konflik yang berarti terhadap penggunaan peribahasa tersebut. Makna 'ketidakpuasan' terbentuk dari struktur luar kalimat yang dibentuk oleh makna leksikal dan struktur gramatikal yang saling berhubungan (Zimin, 1995), dan tidak dapat dipisahkan atau diganti.

Peribahasa Rusia memiliki jumlah sangat banyak meliputi hampir semua aspek kehidupan. Diantara peribahasa-peribahasa tersebut terdapat sejumlah besar peribahasa dengan dan tentang perempuan Rusia, seperti pada contoh (1). Pembahasannya tidak hanya terbatas pada tubuh perempuan, tetapi juga mencapai masalah prilaku, cara pandang, kebiasaan, asmara, perasaan, dll. Jumlah yang besar tersebut, menunjukan kompleksitas kedudukan perempuan dalam budaya Rusia. Jika peribahasa dianggap sebagai inti (peri) bahasa dan bahasa merupakan inti budaya, maka analisis linguakultura terhadap peribahasa Rusia tentang perempuan bertujuan untuk memahami budaya Rusia secara umum, dan kedudukan perempuan Rusia secara khusus. Dalam terminologi linguistik (Rusia), cabang ilmu yang

42 | METAHUMANIORA, Volume 10 Nomor 1, April 2020, 41 - 51 
memfokuskan perhatian pada bahasa sebagai cermin cara pandang, nalar, dan pola pikir sebuah komunitas dikenal dengan linguakulturologi. Secara lebih detail Farkhutdinova (2000) menyatakan bahwa linguakulturologi adalah cabang ilmu linguistik yang mempelajari manifestasi kebudayaan suatu masyarakat ditampilkan oleh bahasa.

\section{METODE PENELITIAN}

Telah disebutkan bahwa peribahasa Rusia berjumlah ribuan. Dalam buku Пословицы русского народа/ "Poslovitsy Russkogo Naroda" yang ditulis oleh V.I. Dahl dari tahun 1853 dan pertamakali dipublikasikan pada tahun 1862 terdapat 30.130 peribahasa yang terkumpul dalam 58 buku meliputi 178 tema. Pribahasa tentang perempuan sendiri, terdapat dalam berbagai tema: tema БАБА - ЖЕНЩИНА/“babazenshina"/'perempuan' memiliki 88 buah peribahasa, ДЕВИЧЬИ ГАДАНЬЯ/“'devichi gadanya”/'teka-teki anak gadis' terdiri dari 35 peribahasa, ЖЕНИХ - HЕВЕСТА/'zenikh - newesta" /'yang menikah - pengantin' terdapat 152 peribahasa, МУЖ - ЖЕНA/" muz-zena" /'suami-istri' memiliki 352 peribahasa, belum termasuk dalam tema yang lain yang jumlahnya bisa ribuan. Pada penelitian ini, beberapa diambil dari kitab peribahasa tersebut, tetapi pengambilan data tersebut didasarkan atas petunjuk dari penelitian-penelitian terdahulu yang menunjukkan kepopuleran peribahasa dalam penggunaan. Secara garis besar, data pada penelitian ini diambil dari referensi-referensi yang digunakan.

Secara umum metode yang digunakan dalam penelitian ini adalah metode kualitatif yang dianggap cukup memadai untuk membongkar masalah sosiohumaniora, termasuk untuk menganalisis peribahasa. Dalam analisis data dan deskripsi penulisan dilakukan dengan paradigma linguakultura. Dalam linguakulturologi, peribahasa menjadi salah satu sumber penting (Gasanova dkk, 2016), untuk menggali informasi budaya yang direfleksikannya. Linguakulturologi sendiri, merupakan termin baru dalam diskursif linguistik (Farkhutdinova, 2000; Fedorov:2014). Meskipun Fedorov (2014) mendefinisikan linguakulturologi sebagai " ... the total sum of culture information objectified in language", tetapi ia menyadari penggunaannya baik sebagai metodologi maupun sebagai paradigma akan sangat bergantung pada tujuan penelitian terhadap aspek budaya yang lebih spesifik. Hal ini berarti, meskipun kulturologi menyajikan paradigma linguistik dalam mengelaborasi bahasa sebagai sumber informasi budaya, ia tetap membutuhkan ilmu-ilmu lain sebagai pendukung.

Fedorov (2014) memformulasikan linguakultura dengan mengutip pendapat Sapir tentang budaya sebagai apa yang dipikirkan oleh masyarakat dan pendapat Leontyev tentang bahasa sebagai sistem pengetahuan. Ia menyimpulkan bahwa tanda-tanda linguistik adalah gambaran kesadaran masyarakat pemakai bahasa. Oleh karena itu, ia memandang bahwa budaya hanya dimengerti dalam dan melalui tanda-tanda bahasa dan dinamikanya. Dalam penelitian ini, tanda-tanda linguistik peribahasa Rusia tentang perempuan akan dibatasi pada dinamika semantik berupa status perempuan dalam relasi sosialnya. Pembatasan ini dilakukan mengingat keterbatasan ruang dan waktu serta tujuan penelitian ini. 


\section{PEMBAHASAN}

Secara sosio-budaya, eksistensi perempuan Rusia diakui dalam relasinya dengan laki-laki atau tepatnya dalam relasinya dalam lingkungan rumah tangga (Sergeyeva, 2012; Palozu; 2014). Hal tersebut juga terjadi pada peribahasa pada bahasa lain. Kerschen (1998: 19) mencatat fakta bahwa “...the overwhelming majority of proverbs that discuss women in a role deal with women as wives". Meskipun terdapat nomina devka, devichka, atau devushka yang berarti gadis atau perawan maka eksistensinya diakui sebagai perempuan yang siap untuk menikah atau dinikahkan. Dalam relasi ini perempuan Rusia diurutkan sebagai berikut: doch (anak perempuan) -devushka -zenshina/baba-mat/machekha -babushka. Di dalam sejarah Rusia, peran perempuan juga mengalami beberapa kali politisasi akibat perubahan kekuasaan. Perubahan besar terjadi pada masa penyebaran agama pravoslav (Kristen Ortodoks) pada abad ke-17, dengan dikeluarkannya aturan Domostroy, yaitu etika rumah tangga dan kehidupan keluarga yang diambil dari ajaran Kristen orthodox. Revolusi Petrin pada abad ke-18 juga memberi dampak pada peran perempuan Rusia, yaitu dengan adanya standar baru perilaku perempuan (Lotman, 1977). Pada masa kekuasaan komunis perempuan dimobilisasi untuk bekerja, akan tetapi eksistensinya tidak mengalami perubahan yang signifikan (Yesenova, 2017).

\subsection{Devka/Devushka/Devichka: (Calon) Perempuan yang Cantik \\ (2) О девке худа не молви \\ "O devke huda ne molvi" \\ 'Tak ada kata yang tak baik menyangkut gadis perawan'}

Dalam peribahasa (2) terdapat kata debкa 'devka' yang secara semantis memiliki makna perempuan yang baik, perawan, cantik, dan bertingkah laku layaknya perempuan secara lahiriah, tidak melakukan penyimpangan prilaku. Kata дebкa 'devka' merepresentasikan bahwa perempuan Rusia patut dihargai dan dijaga sebagai orang yang memiliki peran penting dalam kelangsungan kehidupan, baik itu kehidupan keluarga, bangsa, dan negara. Perempuan dalam peribahasa (1) memiliki peran penting dalam keberlangsungan kehidupan Rusia. Mereka patut dicintai dengan tulus tanpa sedikitpun kata yang menjelekkan, merugikan, dan menyakitinya. Peribahasa (1) sering digunakan dalam konteks ungkapan rasa sayang atau rasa hormat terhadap perempuan. Hal tersebut didasarkan kepada pemikiran, bahwa pada masa ini lah perempuan memiliki eksistensinya sendiri. Kesadaran itu, menempatkan devka atau devushka sebagai mahluk yang rawan sekaligus dipuja.

(3) Девушка не травка, не вырастет без славки

"Devushka ne travka, ne vyrastet bez slavki"

'Perempuan bukan semak belukar, dia tidak tumbuh tanpa burung warbler'

(4) Девушка, гуляй, а своего дела не забывай

"Devushka, gulyaj, a svoego dela ne zabyvaj"

'Gadis ber jalan-jalanlah, tapi jangan lupa tugas' 
(5) Грудь лебедина, походка павлина, очи сокольи, брови соболь

"Grud' lebedina, pohodka pavlina, ochi sokol'i, brovi sobol"

'Dada-angsa, langkah-merak, mata-elang, alis-cerpelai'

Perempuan dalam peribahasa (3 dan 4) direpresentasikan oleh kata девушка "devushka". Kata tersebut merujuk pada perempuan yang belum menikah atau berkeluarga. Selain itu, kata девушка 'devushka' secara semantis bermakna perempuan baik, muda, dan cantik. Peribahasa (3 dan 4) merupakan ungkapan yang mengacu pada takdir kehidupan seorang perempuan, dalam hal ini perempuan selalu menjadi objek pembahasan kaum laki-laki, baik dalam bentuk verbal maupun visual (5). Konsep burung warbler yang selalu berkicau terus dalam interval 5 sampai 15 detik merupakan perumpaan omongan-omongan orang lain. Kata mpabкa 'travka' "rumput liar" merujuk pada tanaman yang kemunculannya tanpa ditanam, dengan kata lain tanaman liar. Perempuan bukanlah semak yang tumbuh tanpa diinginkan, keberadaanya selalu menjadi perhatian.

\subsection{Baba vs Zenshina}

Dalam bahasa Rusia, gambaran sifat buruk perempuan Баба 'baba' berakar kuat: banyak bicara, bodoh, keras kepala, skandal, ingin tahu segala, plin-plan, kasar dan sebagainya. Kata ini bersinonim juga sekaligus berantonim dengan kata женщзина 'zenshina' sebagai perempuan atau istri yang baik.

(6) У бабы волос долог, да ум короток

"U baby volos dolog, da um korotok"

'Perempuan rambutnya panjang, pikirannya yang pendek'

Hampir di setiap budaya, perempuan distereotipkan sebagai mahluk yang lebih banyak bicara daripada bekerja dan suka bergunjing. Selain itu, perempuan pun dicitrakan lebih emosional atau kurang rasional. Ia lebih memikirkan tubuhnya dari pada urusan lain. Stereotip ini melekat terutama pada perempuan Rusia Баба 'baba' pada contoh (6). Bahkan, peribahasa tersebut cukup relevan dengan kondisi perempuan Rusia saat ini yang hanya mementingkan kecantikan, tampilan, dan fisik. Mereka tidak berpikir panjang untuk kemajuan generasi Rusia yang lebih baik. Bagi mereka kehidupan glamour yang didapat dari pasangannya lebih menggiurakan dibandingkan dengan kehidupan keluarga yang baik dan lazim sesuai dengan kultur kehidupan Rusia. Selain itu peribahasa (6) juga relevan dengan kecenderungan perempuan Rusia memilih pasangan sesama jenis karena dianggap lebih sederhana dan tidak menyusahkan hidupnya. Dalam kasus ini perempuan Rusia tidak pikir panjang tentang kehidupan layak bagi seorang perempuan di masa yang akan datang, lagi-lagi mereka hanya mengedepankan kesenangan dan kepuasaan semata.

Hal ini bertentangan dengan citra женщинна 'zenshina', yaitu perempuan dengan standar yang lebih baik. Apabila ditelusuri secara historis, standar ini dapat mengacu kepada Domostroy dan Revolusi Petrine yang menghendaki budaya Rusia meniru budaya Barat atu budaya Eropa pada umumnya. Meskipun demikian, 
eksistensi женщина 'zenshina' juga tetap berada dalam relasi dengan laki-laki atau berada dalam ligkungan rumah tangga.

(7) Женское сердие что котел кипит

"Zhenskoe serdtse chto kotel kipit"

'Hati perempuan bagaikan ketel mendidih'

Peribahasa (7) biasa digunakan untuk mengungkapkan gambaran keinginan dan keadaan psikologis perempuan Rusia. Hati perempuan Rusia diibaratkan sebagai ketel yang mendidih yang dapat memberikan kehangatan dalam secangkir teh, susu, atau kopi. Kehangatan diumpakan sebagai rasa nyaman, tentram, bahagia dan kesuksesan. Dalam budaya Rusia kita mengenal caмobap 'samovar' "semacam ketel untuk membuat the" sebagai simbol kehidupan keluarga Rusia yang harmonis dan berkecukupan (Kirilina, 1998).

Intelektual perempuan Rusia lebih dihargai daripada potensi seksualnya. Jika sudah berkeluarga mereka pasti lebih memilih mengerjakan pekerjaan rumah seperti mencuci pakaian, membersihkan rumah, dan memasak daripada jalan-jalan dan bertemu dengan teman-temannya. Dalam lingkungan keluarga Rusia bekerja di rumah bagi seorang istri merupakan tugas yang lebih mulia dibanding bekerja di kantor. Karena jika dilihat secara porsi waktu, bekerja di rumah lebih banyak menghabiskan waktu yaitu sekitar 76 jam per minggu. Akan tetapi, hal itu bertolak belakang dengan ide-ide feminism. Perempuan Rusia juga harus bekerja di tempattempat yang biasanya dikerjakan oleh laki-laki. Konsep bekerja di Rumah untuk perempuan sudah ada sejak masa imperium Rusia (Yesenova, 2017).

(8) Без мужа женщина, что лошадь без узды

"Bez Muza zenshina, chto losad bez uzdy"

'Perempuan tanpa suami, bagai kuda tanpa kendali'

(9) Без женщины мужчина - что вода без плотин

"Bezzenshinymuzhchina-chtovodabezplotin"

'Lelaki tanpa perempuan, bagai air tanpa gelombang'

Jika keluarga dalam lingkungan perempuan Rusia merasakan kebahagiaan, maka itu akan mempengaruhi kondisi lingkungan sekitarnya yang turut merasakan ketentraman dan kebahagiaan. Perempuan Rusia yang sudah menikah merasa yakin bahwa hubungan keluarga harus berdasarkan cinta yang tulus, romantis, dan cinta yang memberikan harapan kehidupan yang indah di masa depan (8 dan 9). Mereka akan lebih memilih seoarang laki-laki yang berkarakter мужество 'muzestvo' "pria sejati”, yaitu terdapat sifat patuh, adil, lembut, setia, sopan dan bertanggungjawab.

\subsection{Politisasi Peran Perempuan}

Perempuan Rusia tidak tergoda ide-ide feminism. Lebih baik mereka hidup secara naruliah, fokus pada kesejahteraan, kenyamanan, dan ketentraman keluarga. Status mereka sebagai istri sekaligus ibu jauh lebih baik daripada pekerja kantoran. Dalam kehidupan era modern ini yang paling dibutuhkan perempuan Rusia adalah

46 | METAHUMANIORA, Volume 10 Nomor 1, April 2020, 41 - 51 
suami yang pengasih dan bertanggung jawab serta ketenangan dalam keluarga. Mereka tidak memikirkan revolusi perempuan yang memperjuangkan kesetaraan gender seperti yang terjadi di negara-negara barat. Cukup hal itu mereka dengar sebagai bagian dari sejarah yang terjadi pada masa Uni Soviet. Pabноправие nолов/ "Ravnopravie polov" / 'Kesetaraan gender' terdengar tidak menyenangkan bagi mereka (Yesenova, 2017).

Liza Sundstrom dalam koran Riannovosti (2017) menggambarkan sikap perempuan Rusia terhadap feminisme sebagai berikut: Perempuan Rusia percaya bahwa organisasi feminisme terdiri dari perempuan lajang yang radikal dan mungkin lesbian. Mereka menafsirkan feminisme sebagai unifikasi kelamin, penghapusan perbedaan di antara mereka dalam semangat ideologi tertentu. Sejatinya mereka menganggap bahwa gerakan feminisme tidak menyelesaikan masalah-masalah perempuan secara nyata.

(10) Бей бабу молотом - будет баба золотом

"Bej babu molotom - budet baba zolotom"

'Pukulah perempuan dengan palu, maka perempuan akan menjadi emas'

Peribahasa (10) sangat relevan dengan fakta bahwa pada massa kekaisasran Rusia banyak terjadi kekerasan terhadap perempuan. Palu dalam peribahasa (10) berasosiasi dengan kekerasan terhadap perempuan. Kekerasan itu muncul dalam lingkungan keluarga sebagai pelampiasan amarah laki-laki. Saat itu kehidupan keluarga Rusia sangat sulit dan menyakitkan terutama masa-masa menjelang revolusi, di mana banyak terjadi gejolak sosial, ekonomi, dan politik. Sosok perempuan lah yang tetap berdiri tangguh menjalankan roda kehidupan keluarga. Hal itu tercermin dalam karya sastra abad XIX sampai awal abad XX yang direpresentasikan oleh tokoh-tokoh perempuan.

Pada awal masa pemerintahan Federasi Rusia tahun 1990-an terdapat tiga elemen kehidupan yang selalu melibatkan perempuan, yaitu para tokoh, kekuasaan, dan popularitas. Eksistensi ketiga elemen tersebut sangat dipengaruhi oleh perempuan, meskipun dalam hal itu perempuan selalu menjadi "objek" dalam konteks percepatan atau peningkatan kualitas. Secara tidak langsung perempuan menjadi pihak yang selalu ditekan, atau pihak yang dieksploitasi. Di bidang politik, peran perempuan pada tahun tersebut menjadi senjata utama untuk meningkat popularitas. Secara khusus pada abad akhir abad XX orang-orang sudah mulai membicarakan tentang masalah perempuan di Rusia, yang saat hanya dijadikan objek kebijakan para pemangku kepentingan. Lagi-lagi perempuan menjadi emas dalam balutan palu yang terus menghantam.

Upaya untuk mengidentifikasi esensi perempuan Rusia telah dilakukan berkali-kali, terutama dalam karya sastra. Tokoh-tokoh perempuan dalam karya Aleksandr Pushkin digambarkan sebagai perempuan yang setia, jujur, berbudi luhur, romantis, dan kuat dalam eksistensinya. Tokoh-tokoh perempuan dalam karya Nikolai Nyekrasov bertindak sebagai istri dari seorang Dekabrist. Mereka meninggalkan kehidupan salon-salon glamour dan lebih memilih mengajar atau ikut suami mereka ke Siberia dalam perjuangan tanah air. Tokoh Sonya dan Grushenkan 
dalam novel Преступление и наказание/ "Prestuplenie i Nakazanie" / Kejahatan dan Hukuman karya Dostoevsky lebih memilih setia pada suaminya yang mengalami cobaan hidup teramat sulit. Hal itu dilakukan demi cinta dan kesetiaan dalam hubungan keluarga.

Tokoh Anna Karenina merupakan sosok perempuan pertama yang mengorbankan keluarga demi kebahagiaan pribadi. Di masa revolusi 1917 muncul tokoh revolusioner perempuan, yaitu para pekerja dan tahanan kamp konsentrasi dalam karya Maxim Gorky yang memperjuangkan gagasan sosialisme. Paradigma citra perempuan dalam karya fiksi Rusia sebagian besar didasarkan pada nilai-nilai perjuangan bangsa Rusia. Perempuan Rusia selalu menjadi pihak yang tertekan baik itu pribadi, keluarga, dan golongannya. Semakin mereka ditekan dengan kesulitankesulitan yang berat, semakin mereka kuat, bernilai, dan berkarakter.

(11) Курице не быть петухом, а бабе мужиком

"Kuritse ne byt' petuhom, a babe muzhikom"

'Ayam betina tidak akan jadi ayam jantan, tapi perempuan bisa jadi pria tangguh'

Peribahasa (11) sangat populer pada masa pemerintahan Uni Soviet, yang saat itu dikendalikan secara umum oleh partai Bolshevik. Maksud dari peribahasa (11) adalah seorang perempuan dalam kondisi tertentu, termasuk kondisi sulit dan kritispun tetap bisa kuat dan tegas. Peribahasa (9) dapat juga didefiniskan sebagai persamaan peran perempuan dan laki-laki dalam perjuangan membela tanah air. Tepat setelah revolusi 1917, Bolshevik mengeluarkan aturan yang membentuk "manusia baru". Salah satu langkahnya adalah menciptakan dewan perempuan yang dipimpin oleh Aleksandra Kollontay (Yukina, 2003). Dewan tersebut bertugas mencari solusi terhadap masalah perempuan yang muncul pasca revolusi. Solusi yang muncul diantaranya pendidikan khusus perempuan berbasis komunisme, peningkatan aktivitas perempuan dalam perjuangan sosialisme (Yukina, 2003).

(12) Родная сторона - мать, чужая - мачеха;

"Rodnaya storona - mat', chuzhaya - machekha"

'Tanah air adalah ibu, negeri asing adalah ibu tiri'

Kata Mamb/mat/ 'ibu' dalam peribahasa (12) merupakan metafora yang mengungkapkan kecintaan terhadap tanah air, di mana segalanya ada dan patut diperjuangkan. Kata мamb juga berasosiasi dengan simbol perjuangan Rusia saat perang dunia II melawan fasisme Jerman. Slogan-slogan perjuangan juga diisi oleh kata мamъ, contohnya родина - мать зовеm 'podina- mat'zovet' "wahai tanah air, ibu pertiwi memanggil". Slogan tersebut sangat memberikan pengaruh besar terhadap perjuangan Uni Soviet di garis depan, sehingga mampu memukul mundur pasukan Hitler. Peribahasa (5) mendeskripsikan patriotisme Rusia diwakilkan oleh simbol ibu. Peribahasa (5) sangat mencerminkan bangasa Rusia, mereka sangat cinta akan negaranya. Tempat lain di luar negaranya diumpakan sebagai Maчexa 'Machekha' "ibu tiri" yang pada umumnya tidak ada kenyamanan dan keramahan di dalam konsepnya. 
Dalam rangka pembangun pemerintahan baru pasca revolusi, Lenin menyatakan bahwa perempuan memiliki hak yang sama dengan laki-laki. Dia juga mengatakan bahwa perempuan juga turut andil dalam perjuangan sosialisme. Oleh karena itu, mereka berhak atas perhatian lebih. Mereka merupakan titik awal semangat revolusi. Kebijakan Lenin untuk perempuan, diantaranya cuti bagi perempuan hamil, prosedur perceraian disederhanakan, aborsi diizinkan, peningkatan jumlah signifikan perempuan berpendidikan tinggi, dan program penurunan buta huruf kaum perempuan.

Saat Stalin berkuasa di Uni Soviet mulai diberlakukan kontrol pemerintah terhadap kehidupan pribadi. Tahun 1930 Stalin menganggap bahwa masalah perempuan telah selesai, kini negara perlu mengimplementasikan mereka dalam rencana kerja Uni Soviet lima tahun ke depan. Saat itu terdapat slogan" работать на заводе, как машина, а дома рожать, как корова 'rabotat na zavode kak mashina, a doma rozat kak korova' "bekerja di pabrik ibarat mesin, dan produktif di rumah ibarat sapi". Konsekwensi atas seruan ini, terjadi migrasi perempuan dari desa ke kota. Mereka selalu dilibatkan di pabrik dan pertanian kolektif. Selain itu, perempuan mulai bekerja dalam profesi yang sebelumnya hanya bagi laki-laki (maskulin) seperti supir, petugas jaga, pengemudi truk, pengemudi traktor, masinis, dll. Pada saat yang sama, terjadi revolusi seksual yang digagas oleh sebagian kecil kaum perempuan. Tuntunan mereka diantaranya pelarangan aborsi, pembatasan distribusi alat kontrasepsi, usulan prosedur perceraian yang rumit. Semua itu merupakan upaya peningkatan populasi dan meminimalisir kejahatan sosial terhadap kaum perempuan Rusia (Yukina, 2003).

(13) Скачет баба задом и передом, а дело идет своим чередом

"Skachet baba zadom i peredom, a delo idet svoim cheredom"

'Perempuan loncat sana sini, segalanya berjalan dengan caranya sendiri'

Peribahasa (13) sangat populer saat Uni Sovyet dipimpin oleh Nikita Krushev. Makna semantis peribahasa (13) adalah semua urusan harus diselesaikan oleh perempuan dengan caranya sendiri, tidak diatur oleh negara seperti pada era Stalin, meskipun di sisi lain perempuan juga punya hak untuk bekerja ataupun melakukan aktivitas yang bersifat hiburan. Krushev memberikan hak otonomi pada setiap keluarga Rusia, khususnya dalam hal mendidik anak dan keberlangsungan kehidupan keluarga. DiantaranyaPenghapusan kerja kolektif, maka seorang ibu memiliki waktu yang lebih untuk mengabdi pada keluarga. Pada masa pemerintahan Krushev juga mulai terjadi liberalisasi parsial, misalnya hak aborsi kembali diberikan kepada perempuan, akan tetapi hal itu dilakukan tanpa anestasi dan obat penghilang rasa sakit. Hal ini sebenarnya diberlakukan untuk mencegah aborsi itu sendiri.

Pada periode Khrushev, negara mengeluarkan program bantuan untuk ibu dengan status single parent, janda dan perempuan hamil. Ini bukan hanya sebuah kebijakan untuk meningkatkan angka kelahiran, tetapi juga merupakan bagian dari proyek ideologis baru di dunia "ibu bekerja". Hal itu juga merupakan propaganda yang dirancang untuk membujuk perempuan supaya berpartisipasi secara aktif dalam kehidupan sosial dan mempromosikan peran ibu secara tradisional, yaitu вернуть женщин $b$ семью 'vernut zenshin $\mathrm{v}$ semyu' "kembalikan perempuan ke keluarga." Tetapi karena mereka tidak bisa dan tidak mau berhenti bekerja, mereka 
harus bekerja dua kali lebih banyak daripada laki-laki (pekerjaan, rumah dan anakanak). Konsep "ibu bekerja" secara historis bertentangan dekan gerakan antifeminisme. Gerakan tersebut dianggap sebuah propaganda pemerintah untuk meningkatkan kualitas dan kesetiaan dalam pernikahan.

(14) Знай, баба, свое кривое веретено

"Znaj, baba, svoe krivoe vereteno"

'Perempuan harus tahu jika hakpennya bengkok'

Peribahasa (14) secara semantis memiliki makna bahwa seorang perempuan harus bersikap, bertindak, bekerja layaknya seorang perempuan secara lahiriah dan tradisi Rusia. Seni merajut pakaian sudah menjadi tradisi yang berkembang di Rusia sejak massa kekaisaran sampai Federasi Rusia. Kata Веретено 'vereteno' secara leksikal bermakna alat untuk merajut yang terbuat dari bahan kayu. Веретено bisa dikatakan sebagai benda yang selalu melekat pada citra perempuan Rusia. Mereka yang mampu merajut pakaian, maka disebut sebagai perempuan Rusia yang patuh akan tradisi Rusia. Jika веретено yang dimilikinya bengkok, maka itu sebuah petanda ada yang tidak beres dalam hidupnya.

Selama periode perestroika, politik diorientasikan ke arah tradisional, pembagian peran laki-laki dan perempuan dan mendorong perempuan Rusia untuk kembali ke rumah. Langkah tersebut merupakan upaya untuk melestarikan tradisi kehidupan perempuan Rusia. Secara sosial hal itubertujuan untuk menciptakan suasana kehidupan keluarga yang sehat dan harmonis, di mana semua aktivitas harian dimulai oleh peran ibu.

Kebijakan Uni Soviet selama periode perestroika paling baik diilustrasikan oleh kata-kata dari pidato Gorbachev 1987 (Trizman, 2012): “Kami telah kehilangan pandangan tentang hak-hak khusus dan kebutuhan seorang perempuan terkait dengan perannya sebagai seorang ibu, nyonya rumah keluarga, fungsinya yang tak tergantikan dalam membesarkan anak-anak. Seorang perempuan yang bekerja di bidang konstruksi, manufaktur, dan sektor jasa diserap dalam pekerjaan kreatif dan sama sekali tidak punya cukup waktu untuk membereskan aktivitas rumahan seharihari. Hal itu ternyata malah menimbulkan banyak masalah, terutama dikaitkan dengan melemahnya ikatan keluarga. Inilah paradoks yang terjadi, meskipun Rusia memiliki keinginan untuk menyamakan perempuan dengan pria dalam segala ha, tetapi hal itu merupakan kelalaian dari kebajikan dan harus mulai dikoreksi melalui gagasan perestroika. Pertanyaan tentang bagaimana untuk kembali sepenuhnya menjadi seorang perempuan Rusia sejati adalah bagian dari tugas mulia negera.

\section{PENUTUP}

Kerschen (1998) telah menggarisbawahi bahwa dalam peribahasa pada umumnya, eksistensi perempuan berelasi dengan pernikahan atau ketika ia berkedudukan sebagai istri. Bukan suatu kebetulan, pendapat tersebut dalam linguakultura peribahasa Rusia terlihat jelas. Bagi kaum feminist, peribahasa dan bahasa pada umumnya diciptakan dan memakai bahasa laki-laki (baca misalnya, $A n$ Ethic of Sexual Difference karya Luce Irigaray, 1984). Meskipun tulisan ini tidak didasarkan kepada studi gender, tetapi dapat dikatakan ikut mengafirmasi kondisi tersebut.

50 | METAHUMANIORA, Volume 10 Nomor 1, April 2020, 41 - 51 
Dengan menganalisis satuan semantik posisi perempuan secara sosial, stereotifakasi dan persepsi perempuan Rusia dalam peribahasa bukan saja memberikan gambaran tetapi menguatkan betapa besarnya kuasa laki-laki atau budaya patriarki dalam masyarakat Rusia baik dalam dimensi folklor maupun dimensi kekuasaan. Hal ini dibenarkan oleh Varonina (1997), Zakirova (2014), dan banyak peneliti lainnya. Varonina (1997) menyatakan “...the true of democrazisation of Russian society requires rejection of masculinist ideology...." Pernyataan ini mengindikasikan latar belakang budaya patriarki di Rusia.

Bagi Mieder (2004) membaca dan menganalis peribahasa dapat menberikan gambaran budaya, "As informative and useful signs of cultural values and thoughts". Pandangan mengenai perempuan dalam peribahasa Rusia--setidaknya dalam tinanda semantik--yang disajikan dalam penelitian ini memberi gambaran tentang pola pikir dan nilai budaya yang tidak saja terdistorsi oleh penilaian laki-laki, tetapi juga menjadi bias yang pervasive.

\section{DAFTAR PUSTAKA}

Dahl, V.I. 2003. Russian Proverbs. Moscow: Eksmo Press.

Farkhutdinova, F. 2000. Vzglyanut' na mir skvoz' prizmu slova: opyt lingvokul' turologicheskogo analiza russkosti. Ivanovo: IvSU Press.

Fedorov, M.A. 2014. Termin "Lingukultura" v Aspekte TeoriiKultury. Vestnik Buryatskogo gasudarstennogo Universiteta. 6(2)/2014

Irigaray, Luce. 1984. An Ethics of Sexual Difference. Cornell University Press

Kerschen, Lois, 1998. American proverbs about women. A reference guide. Westport, Connecticut, London: Greenwood Press.

Kirilina A. V. 1998. Gendernye Stereotipy, Rechevoe Obshchenie I Delovaya Leksika I Imidzh Zhenshchiny-Lidera: Kollektivnaya Monografiya. Ivanovo: IvSU Press

Mieder, W. 2008. Proverbs Speak Louder Than Words: Wisdom In Art, Culture, Folklor, History, Literature and Mass Media. York: Peter Lang.

Permyakov, G.L. 1988. Fundamentals of structural paremiology. Moscow: Nauka.

Sergeyeva, Alla. 2012. Russkie: Stereotipy Povedeniya, Tradisi, Mentalnost. Moskwa: Flinta.

Trizman, D. 2012. Istoriya Rossii. Ot Gorbacheva do Putina i Medvedeva. Moskva: Eksmo.

Voronina, O. 1993. "Soviet Patriarchy: Past and Present". Hypatia, 8(4), 97-112. Retrieved April 15, 2020, from www.jstor.org/stable/3810373

Venera, Zakirova. 2014. "Gender inequality in Russia: the perspective of participatory gender budgeting". Reproductive Health Matters. 22:44, 202 212, DOI: 10.1016/S0968-8080(14)44806-7

Yesenova, T. S. 2017. Androtsentrizm gendernykh stereotipov na primere paremii. Jurnal of Kalmyk University. 34(2): 86-92.

Yukina, Irina. 2003. Istoriya zhenshchin v Rossii. St. Petersburg: Aleteya

Zimin, V. I. 2005. Poslovitsy i pogovorki russkogo naroda. Bol'shoj tolkovyj slovar'. Rostov: Feniks 